University of Nebraska - Lincoln

DigitalCommons@University of Nebraska - Lincoln

December 1994

Electron-beam-induced patterned deposition of allylcyclopentadienyl palladium using scanning tunneling microscopy

\author{
D.S. Saulys \\ Rutgers University
}

A. Ermakov

Rutgers University, Piscataway, New Jersey

E.L. Garfunkel

Rutgers University, Piscataway, New Jersey

Peter A. Dowben

University of Nebraska-Lincoln, pdowben@unl.edu

Follow this and additional works at: https://digitalcommons.unl.edu/physicsdowben

Part of the Physics Commons

Saulys, D.S.; Ermakov, A.; Garfunkel, E.L.; and Dowben, Peter A., "Electron-beam-induced patterned deposition of allylcyclopentadienyl palladium using scanning tunneling microscopy" (1994). Peter Dowben Publications. 53.

https://digitalcommons.unl.edu/physicsdowben/53

This Article is brought to you for free and open access by the Research Papers in Physics and Astronomy at DigitalCommons@University of Nebraska - Lincoln. It has been accepted for inclusion in Peter Dowben Publications by an authorized administrator of DigitalCommons@University of Nebraska - Lincoln. 


\title{
Electron-beam-induced patterned deposition of allylcyclopentadienyl palladium using scanning tunneling microscopy
}

\author{
D. S. Saulys, A. Ermakov, and E. L. Garfunkel \\ Department of Chemistry, the Laboratory for Surface Modification, Rutgers University, Piscataway, \\ New Jersey 08855-0939 \\ P. A. Dowben \\ Behlen Laboratory of Physics, Department of Physics, University of Nebraska, Lincoln, \\ Nebraska 68588-0111
}

(Received 31 May 1994; accepted for publication 13 August 1994)

Scanning tunneling microscopy has been used to study the electron-induced decomposition of allylcyclopentadienyl palladium $\left[\mathrm{Pd}\left(\eta^{3}-\mathrm{C}_{3} \mathrm{H}_{5}\right)\left(\eta^{5}-\mathrm{C}_{5} \mathrm{H}_{5}\right)\right]$ and subsequent deposition on a $\mathrm{Si}(111)$ surface. Deposition occurs via an electron impact mechanism on either the tip or surface, depending on the bias polarity, and is observed with voltages of $\geqslant 2.75 \mathrm{~V}$. This is close to the predicted condensed phase dissociation energy of $2.3 \mathrm{eV}$ for $\mathrm{Pd}\left(\eta^{3}-\mathrm{C}_{3} \mathrm{H}_{5}\right)\left(\eta^{5}-\mathrm{C}_{5} \mathrm{H}_{5}\right) \rightarrow \mathrm{Pd}+\mathrm{C}_{3} \mathrm{H}_{5}+\mathrm{C}_{5} \mathrm{H}_{5}$. Metallic deposits of nanometer dimensions can be written on the surface. Deposition onto an electrochemically etched tip results in a narrow conductive secondary tip which gives improved spatial resolution when imaging high-aspect ratio features on the surface. (C) 1994 American Institute of Physics.

Noble metal deposition on semiconductor surfaces is of interest in several technological applications, including the manufacture of microelectronic devices. Current lithographic techniques yield devices with submicron lateral dimensions. ${ }^{1}$ Smaller devices require nonconventional methods of metallization such as e-beam direct writing. ${ }^{2}$ Nanometer-sized metal features may also be used to test simple models of quantum-well states ${ }^{3}$ and wires. ${ }^{4}$ In addition, there is also the intriguing possibility that very small features (i.e., clusters) of metal normally thought of as paramagnetic (e.g., palladium or rhodium) might be ferromagnetic. ${ }^{5}$

Direct writing of metallic features has been accomplished by decomposing an organometallic with a narrow beam of electrons or photons. ${ }^{6}$ Scanning tunneling microscopy (STM) offers a convenient, extremely narrow electron beam source and has been successfully used to deposit features containing $\mathrm{Cd}, \mathrm{Fe}, \mathrm{Al}$, and $\mathrm{B} .{ }^{7}$ In our studies we use an STM to decompose allylcyclopentadienyl palladium $\left[\mathrm{Pd}\left(\mathrm{C}_{3} \mathrm{H}_{5}\right)(\mathrm{CP})\right]$ on a silicon surface to give nanometer-sized patterned features.

Allylcyclopentadienyl palladium was chosen based on the results of previous studies by Dowben and others. ${ }^{8-11}$ The decomposition energetics were determined by bombarding the gas-phase molecule with electrons and photons of varying energy and monitoring the distribution of fragments in a mass spectrometer. ${ }^{9,10}$ From this and other work, ${ }^{10}$ it was concluded that the organic ligands could be cleanly removed from the metal atom with photons and electrons in the energy range easily accessible by STM; that is, several $\mathrm{eV}$ with a threshold energy of $2.3 \mathrm{eV}$ for the condensed phase dissociation. Other studies investigated the blanket and patterned deposition of Pd films ( $>95 \%$ purity as determined by Auger electron spectroscopy, AES) using an ultraviolet laser., 8,911

In our studies, we demonstrate that STM-induced deposition can occur on either the tip or surface, depending on the bias polarity. Patterns deposited on the surface are observed directly by switching the STM from use as an electron-beam source for deposition to an imaging mode. Deposition on the tip results in the creation of a higher aspect ratio secondary tip, made evident as improvements in the resolution of the STM images. The polarity dependence suggests a simple electron impact mechanism of decomposition and subsequent deposition.

All experiments were conducted in a UHV (ultrahigh vacuum) system with a base pressure of $4 \times 10^{-11}$ Torr. The $\mathrm{Pd}\left(\mathrm{C}_{3} \mathrm{H}_{5}\right)(\mathrm{Cp})$ was synthesized using the method described by Shriver. ${ }^{12}$ The silicon (111) was $p$ type (boron-doped to 5-10 $\Omega \mathrm{cm}$ ), with a $4^{\circ}$ miscut and was cleaned following conventional procedures. ${ }^{13}$

The surface was imaged using tunneling conditions of 1 nA current and +2 to $+4 \mathrm{~V}$ sample bias. To deposit, the tip was retracted and the compound was introduced into the chamber through a leak valve until an ion gauge reading of $1 \times 10^{-6}$ Torr. Compound exposure was concentrated at the surface with a Teflon tube doser and the local pressure was estimated to be $10^{-5}$ Torr. The bias was adjusted and the tip brought back into range. The tip was then scanned in a particular pattern and after a few minutes it was retracted again, the leak valve closed, and the same area once again imaged with STM.

The manifestation of deposition onto the tip is given in Fig. 1. Figure 1(a) shows an area of the $p$-type Si(111) miscut by $4^{\circ}$ displaying ordered steps and several defect features. Figure 1(b) shows the much improved resolution of these features after a new and sharper secondary tip was deposited using a sample bias of $-10 \mathrm{~V}$ and setpoint current of $1 \mathrm{nA}$.

The resolution of an STM image, especially in the lateral directions for high-aspect ratio features, is limited by the shape and sharpness of the tip. ${ }^{14}$ In Fig. 1 we see features on a surface apparently get sharper after we deposit onto the tip. The features and steps are in the exact same places in the two images; only the defect sharpness has changed. This is not due to a change on the surface but rather to the deposition on 

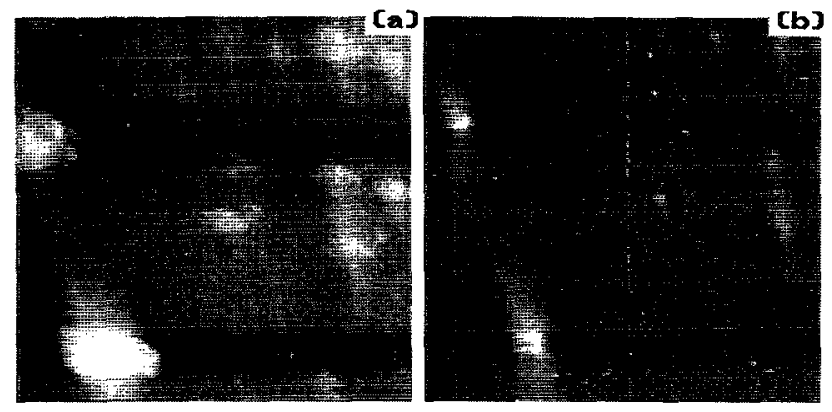

FIG. 1. STM images demonstrating deposition on the tip. (a) shows an STM topograph of the $\mathrm{Si}(111)$ surface before deposition onto the tip. (b) shows the same area after deposition to the tip. Height is indicated by the gray scale, with lighter regions indicating higher areas and darker regions showing low areas. The total area shown is $680 \times 680 \mathrm{~nm}^{2}$ and the tallest features are $60 \AA$ high. The faint diagonal lines seen running from the upper left to lower right are monatomic steps of $2-3 \AA$ height and $20-40 \AA$ width.

the tip leaving us with a narrower conductive secondary tip.

Deposition onto the surface was performed using a positive sample bias. Figure 2 is a topographic image of a ring deposited on the surface using $+10 \mathrm{~V}$ sample bias and $1 \mathrm{nA}$ current. During deposition the STM tip was scanned in a circle for $5 \mathrm{~min}$ at a frequency of about $1 \mathrm{~Hz}$.

Tip sharpening (i.e., deposition on the tip) with no surface deposition was observed when electrons flowed from the sample to the tip (negative sample bias). Conversely, surface deposition without tip deposition was observed with the opposite bias polarity. At least two mechanisms can explain these results:

electron-induced heating: electrons accelerated onto a material heat it, leading to thermally-induced decomposition of adsorbed molecules; and electronic excitation: decomposition of the Pd com-

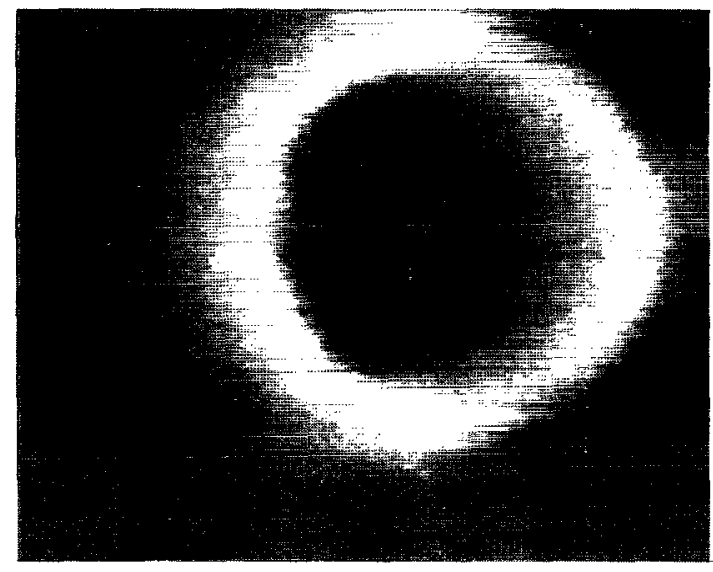

FIG. 2. Ring deposited on the surface. This feature was created by applying sine-wave voltage ramps to the $x$ and $y$ sections of the scanning tube during deposition, which rastered the tip in a circle at a frequency of $1 \mathrm{~Hz}$. The ring has an outer diameter of $220 \mathrm{~nm}$, a thickness of $50 \mathrm{~nm}$ FWHM and is $6 \mathrm{~nm}$ high.
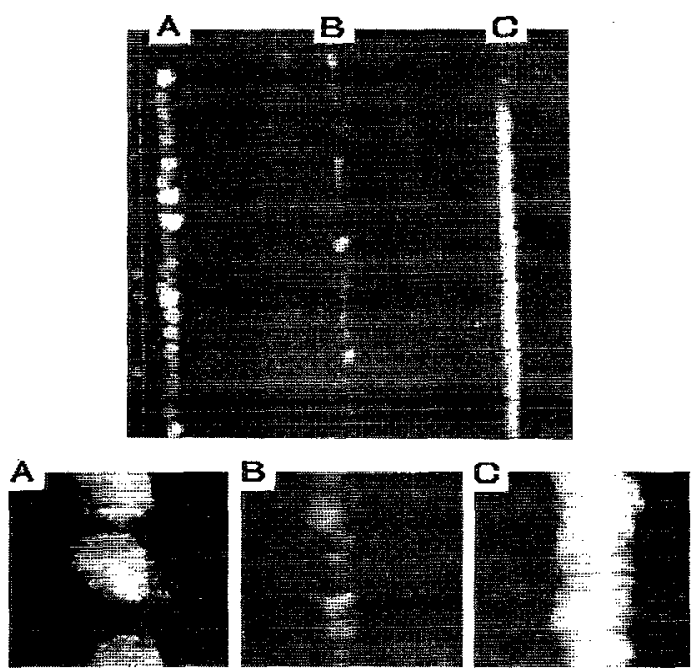

FIG. 3. Three lines deposited on the surface. These were deposited with different voltages and/or numbers of scans. Again, the tip was rastered in the $y$ direction at a speed of $350 \AA / \mathrm{s}$. Line $\mathrm{A}$ was deposited at $+3 \mathrm{~V}$ sample bias with 20 scans. Lines $B$ and $C$ were both deposited with $+4 \mathrm{~V}$ bias. Line $B$ was drawn with 2 scans and line $C$ was drawn with 20 scans. The large area shown is $1260 \times 1260 \mathrm{~nm}^{2}$, the lines are ca. $50 \mathrm{~nm}$ wide and the tallest features are $10 \mathrm{~nm}$ high.

pound is caused by the bombardment of sufficiently energetic electrons on adsorbed molecules.

Pd was deposited using different setpoint currents and the amount of material deposited (hence deposition rate) increased with increasing current. This dependence is consistent with either the thermally induced or electronic excitation decomposition mechanism. With electron-induced heating, the heating, and hence deposition rate, would be proportional to setpoint current. Likewise for electronic excitation, increased setpoint current corresponds to greater electron density allowing for more collisions with adsorbed molecules. Unfortunately for STM, increasing the setpoint current also decreases the tip-sample distance. This can result in adsorption limited "tip shadowing" regime that leads to fewer adsorbed molecules between the tip and sample, and hence lower the deposition rate. Thus, a simple power-dependence analysis is inconclusive. However, we favor an electronexcitation mechanism as the threshold for deposition was found to be ca. $2.75 \mathrm{~V}$, which is close to the condensed phase dissociation energy of $2.3 \mathrm{eV}$ for $\mathrm{Pd}\left(\mathrm{C}_{3} \mathrm{H}_{5}\right)(\mathrm{Cp}) \rightarrow \mathrm{Pd}+\mathrm{C}_{3} \mathrm{H}_{5}+\mathrm{Cp}$.

Three lines deposited by rastering the STM tip only in the $y$ direction are shown in Fig. 3. Line A was deposited at $+3 \mathrm{~V}$ sample bias with 20 scans, line $\mathrm{B}$ at $+4 \mathrm{~V}$ with 2 scans, and line $\mathrm{C}$ at $+4 \mathrm{~V}$ at 20 scans. Deposition starts unevenly along the scanned direction, resulting in small globular deposits which eventually fill in to form a continuous line.

The discontinuous structure of the palladium lines drawn with the STM is characteristic of the formation of nucleation centers. Two mechanisms favor inhomogeneous growth at nucleation sites rather than homogeneous growth along the tip path. First, the palladium that is initially deposited may 

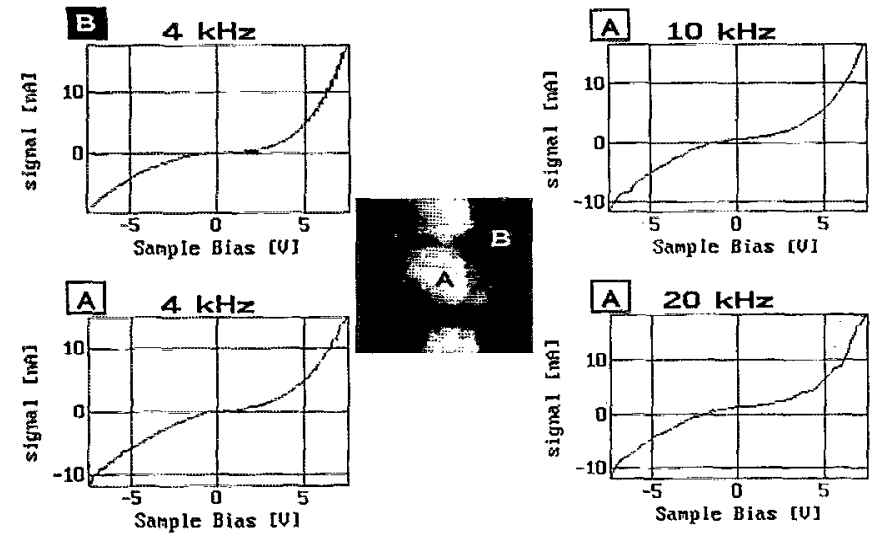

FIG. 4. Current vs voltage curves. These curves show how the tunneling current changes as the bias voltage is ramped while keeping the tip-sample distance fixed. The top left-hand curve is of the clean Si(111) surface. The remaining curves are of the deposited area but with different bias-ramp rates.

form catalytically active sites for the further decomposition of the organometallic; thus reactivity is enhanced at initial deposition sites relative to the clean $\mathrm{Si}$ substrate. Second, perhaps even more important, the initial nucleation sites should be especially reactive since their protrusion from the surface results in an inhomogeneous electric field between the tip and surface during deposition. Electrons emitted from the tip will be refocused onto the deposits, increasing the deposition rate at these sites in comparison to the surrounding surface.

$I-V$ curves comparing the clean silicon surface to the deposits are given in Fig. 4. In our fixed-position tunneling spectroscopy experiment, the STM tip is brought within tunneling range, the feedback is turned off, and the current is measured as the bias is varied. The curve in the upper left corner is that of the $p$-type $\mathrm{Si}$ and shows the expected behavior. The wide "inflection point" showing zero current for a small range of biases centered around $0 \mathrm{~V}$ is indicative of the band gap.

The remaining three curves are $I-V$ curves of the deposit at different sampling rates. Each increase in sampling rate means an increase in the speed of bias ramping. This behavior simulates what might be predicted for a metallic deposit on a highly doped Si surface, an ohmic contact with slightly capacitive behavior. As the bias ramp rate is increased, we see a corresponding increase of residual current near $0 \mathrm{~V}$ as the charge is lemporarily stored in the deposit or tip before discharging into the substrate.

Finally we note that, when AES was done over a relatively large area $\left(>1 u \mathrm{~m}^{2}\right)$, Pd was clearly seen in the spectrum. Also, the clean deposition of $\mathrm{Pd}$ from this compound at relatively low energies $(3.68 \mathrm{eV})$ has already been demonstrated. $^{9}$

We have demonstrated the direct writing of nanometersized features on a $\mathrm{Si}(111)$ surface using $\mathrm{Pd}\left(\mathrm{C}_{3} \mathrm{H}_{5}\right)(\mathrm{Cp})$ as a precursor molecule. The $\mathrm{Pd}$ compound is decomposed via an electron impact mechanism using an STM as the electron beam source. Metallic features may be deposited on the surface or tip depending on the bias polarity used. We have demonstrated deposition of both lines and a ring structure. It would be possible to deposit almost any pattern by using the appropriate voltage waveforms to drive the piezoelectric scanning tube of the STM. Deposition onto the tip leads to a sharper secondary tip which is conductive. The new tip demonstrates a significant improvement in the resolution of highaspect ratio features. This could be generalized to other systems in which a simple method for in-situ tip growth/ sharpening is needed.

D.S., A.E., and E.G. acknowledge NSF-DMR No. 9306899 for support of this work, and P.D. acknowledges AFSOR for support.

${ }^{1}$ P. Burggraaf, Semicond. Int. 16, 38 (1993); T. Terasawa, N. Hasegawa, and T. Toshihiko, J. Vac. Sci. Technol. B 8, 13 (1990); M. D. Levenson, Physics Today 46, 28 (1993).

${ }^{2}$ A. N. Broers, in Nanostructure Physics and Fabrication, edited by M. A. Reed and W. P. Kirk (Academic, New York, 1989), p. 421; A. N. Broers, W. W. Molzen, J. J. Cuomo, and N. D. Wittels, Appl. Phys. Lett. 29, 596 (1976).

${ }^{3}$ D. S. Chuu, C. M. Hsiao, and W. N. Mei, Phys. Rev. B 46, 3898 (1992); M. Wagner, U. Merkt, and A. V. Chaplik, Phys. Rev. B 45, 1951 (1992); Y. V. Nazarov and A. V. Khaetskii, Phys. Rev. B 49, 5077 (1994).

${ }^{4}$ O. Niu, Phys. Rev. Lett. 64, 1812 (1990).

${ }^{5}$ A. J. Cox, J. G. Louderback, and L. A. Bloomfield, Phys. Rev. Lett. 71, 923 (1993); B. V. Redd, S. N. Khanna, and B. A. Dunlap, Phys. Rev. Lett. 70, 3323 (1993).

${ }^{6}$ P. A. Dowben, J. T. Spencer, and G. T. Stauf, Mat. Sci. Eng. B 2, 297 (1989); J. T. Spencer, in Progress in Inorganic Chemistry, edited by K. D. Karlin (1994), Vol. 41, p. 145.

${ }^{7}$ (a) $\mathrm{Cd}(\mathrm{Me})_{2}$ : E. E. Ehrichs, S. Yoon, and A. L. deLozanne, Appl. Phys. Lett. 53, 2287 (1988); E. E. Ehrichs, R. M. Silver, and A. L. deLozanne, J. Vac. Sci. Technol. A 6, 540 (1988); R. M. Silver, E. E. Ehrichs, and A. L. deLozanne, Appl. Phys. Lett. 51, 247 (1987); (b) $\mathrm{Fe}(\mathrm{CO})_{5}$ : A. D. Kent, T. M. Shaw, S. von Molnar, and D. D. Awschalom, Science 262, 1249 (1993); M. A. McCord and D. D. Awschalom, Appl. Phys. Lett. 57, 2153 (1990); D. D. Awschalom, M. A. McCord, and G. Grinstein, Phys. Rev. Lett. 65, 783 (1990); (c) $A l(M e)_{3}$ : E. E. Ehrichs and A. L. deLozanne, in Nanostructure Physics and Fabrication, edited by M. A. Reed and W. P. Kirk (Academic, New York; 1989), p. 441; S.-T. Yau, D. Saltz, and M. H. Nayfeh, Appl. Phys. Lett. 57, 2457 (1990); (d) $B_{10} H_{14}$ : G. Dujardin, R. E. Walkup, and P. Avouris, Science 255, 1232 (1992); P. Avouris, I.-W. Lyo, F. Bozso, and E. Kaxiras, J. Vac. Sci. Technol. A 8, 2405 (1990); F. K. Perkins, M. Onellion, S. Lee, and P. Dowben, in Photons and Low Energy Particles in Surface Processing, edited by C. J. H. Ashley, J. H. Brannon, and S. W. Pang (MRS, Pittsburgh, PA, 1992), Proc. 236, p. 153.

${ }^{8}$ G. T. Stauf and P. A. Dowben, Thin Solid Films 156, L31 (1988).

${ }^{9}$ G. T. Stauf, P. A. Dowben, K. Emrich, S. Barfuss, W. Hirschwald, and N. M. Boag, J. Phys. Chem. 93, 749 (1989).

${ }^{10}$ K.-H. Emrich, G. T. Stauf, W. Hirschwald, S. Barfuss, P. A. Dowben, R. R. Birge, and N. M. Boag, in Chemical Perspectives of Microelectronic Materials, edited by M. Gross, J. Jasinkiand, and J. T. Yates (MRS, Pittsburgh, PA, 1989), Prnc. 131, p. 401.

${ }^{11}$ S.-D. Hwang, Y.-G. Kim, C. Wu, and P. A. Dowben, Mat. Sci. Eng. B 20, LI (1993); Y.-G. Kim, S. Bialy, G. T. Stauf, R. W. Miller, J. T. Spencer, P. A. Dowben, and S. Datta, J. Micromech. Microeng. 1, 42 (1991).

${ }^{12}$ D. F. Shriver, Inorganic Syntheses 19, 220 (1979).

${ }^{13}$ B. S. Swartzentruber, Y.-W. Mo, M. B. Webb, and M. G. Lagally, J. Vac. Sci. Tcchnol. A 7, 2901 (1989).

${ }^{14}$ D. Keller, Surf. Sci. 253, 353 (1991); G. Reiss, F. Schneider, J. Vancea, and H. Hoffman, Appl. Phys. Lett. 57, 867 (1990); P. Niedermann and O. Fischer, J. Microsc. 152, 93 (1988). 